\title{
O USO DA ROBÓTICA NA PERSPECTIVA DA EDUCAÇÃO MATEMÁTICA INVENTIVA
}

\author{
THE USE OF ROBOTICS IN THE PERSPECTIVE OF \\ INVENTIVE MATHEMATICAL EDUCATION
}

\section{EL USO DE LA ROBÓTICA EN LA PERSPECTIVA DE LA \\ EDUCACIÓN MATEMÁTICA INVENTIVA}

Marcos Roberto da Silva ${ }^{1}$, Arlindo José de Souza Junior ${ }^{2}$

\section{RESUMO}

Ao abordarmos a problemática voltada a maneira como os estagiários de um Curso de Licenciatura em Matemática desenvolveram e aplicaram algumas propostas educacionais de matemática com o uso da robótica, emergiu de nossa pesquisa de doutorado o que denominamos como Educação Matemática Inventiva. Neste contexto, revelamos no presente artigo, como os estagiários desenvolveram coletivamente algumas propostas educacionais, segundo a perspectiva da Educação Matemática Inventiva, a partir da construção e programação de três robôs, denominados como: Robô Seguidor de Linha, Robô Empilhadeira e Robô Separador. Durante a pesquisa os estagiários fizeram uso destes robôs com o propósito de desenvolverem propostas educacionais e aplicá-las em duas escolas-campo de estágio da rede pública de ensino. As propostas educacionais foram desenvolvidas coletivamente pelos estagiários com o uso da robótica a partir das necessidades específicas de aprendizagem de cada turma de alunos, posteriormente foram aplicadas nas escolas-campo de estágio. Constatamos durante as experiências ocorridas no espaço-tempo do estágio-docência, que a robótica foi utilizada pelos estagiários de forma inventiva durante a produção e aplicação de suas propostas educacionais. O uso da robótica pelos estagiários foi significativo para o desenvolvimento de ações e práticas de Educação Matemática Inventiva.

PALAVRAS-CHAVE: Educação Matemática Inventiva. Robótica. Propostas educacionais de matemática. Estágio.

\begin{abstract}
Addressing the problematic of how the Mathematics' trainees from a Degree Course developed and applied some educational proposals of mathematics with the use of robotics emerged from our doctoral research what we call as Inventive Mathematical Education. In this context, we reveal in this article how the trainees collectively developed some educational proposals, according to the perspective of Inventive Mathematical Education, from the construction and programming of three robots, denominated as: Line Follower Robot, Forklift Robot and Separator Robot. During the research, the trainees made use of these robots for the purpose of developing educational proposals and applying them in two camp schools of the public-school system. The educational proposals developed collectively by the trainees with the use of robotics from the specific learning needs of each class of students, later they were applied in the field schools of the stage. We found during experiments in the space-time of the teaching-stage that robotics was used by the trainees in an inventive way during the production and application of their educational proposals. The use of robotics by trainees was significant for the development of actions and practices of Inventive Mathematics Education.
\end{abstract}

KEYWORDS: Inventive Mathematics Education. Robotics. Mathematical educational proposals. Internship.

\footnotetext{
${ }^{1}$ Doutor em Educação - Universidade Federal de Uberlândia (UFU). Uberlândia, MG - Brasil. Docente Universidade Estadual de Goiás (UEG). Anápolis, GO - Brasil. E-mail: marcos.silva@ueg.br

${ }^{2}$ Doutor em Educação - Universidade Estadual de Campinas (UNICAMP). Campinas, SP - Brasil. Professor titular da Universidade Federal de Uberlândia (UFU). Uberlândia, MG - Brasil. E-mail: arlindoufu@gmail.com
}

Submetido em: 01/03/2019 - Aceito em: 20/12/2019 


\section{RESUMEN}

Al abordar la problemática orientada a la manera como los pasantes de un Curso de Licenciatura en Matemáticas desarrollaron y aplicaron algunas propuestas educativas de matemáticas con el uso de la robótica, emergió de nuestra investigación de doctorado lo que denominamos Educación Matemática Inventiva. En este contexto, revelamos en el presente artículo, como los pasantes desarrollaron colectivamente algunas propuestas educativas, según la perspectiva de la Educación Matemática Inventiva, a partir de la construcción y programación de tres robots, denominados como: Robot Seguidor de Línea, Robot Apiladora y Robot Separador. Durante la investigación los pasantes hicieron uso de estos robots con el propósito de desarrollar propuestas educativas y aplicarlas en dos escuelas-campo de práctica de la red pública de enseñanza. Las propuestas educativas fueron desarrolladas colectivamente por los pasantes con el uso de la robótica a partir de las necesidades específicas de aprendizaje de cada clase de alumnos, posteriormente fueron aplicadas en las escuelas-campo de práctica. Constatamos durante las experiencias ocurridas en el espacio-tiempo de la etapadocencia, que la robótica fue utilizada por los pasantes de forma inventiva durante la producción y aplicación de sus propuestas educativas de matemáticas. El uso de la robótica por los pasantes fue significativo para el desarrollo de acciones y prácticas de Educación Matemática Inventiva.

PALABRAS-CLAVE: Educación Matemática Inventiva. Robótica. Propuestas educativas de matemáticas. Pasantía.

\section{INTRODUÇÃO}

O presente trabalho faz parte de uma pesquisa de doutorado em Educação que se originou da necessidade de buscarmos na robótica uma alternativa em relação as práticas formativas focadas no modelo da representação ${ }^{3}$. Em nossas experiências desenvolvidas no estágio-docência, consideramos o termo robótica como "o estudo dos robôs, o que significa que é o estudo da sua capacidade de sentir e agir no mundo físico de forma autônoma e intencional" (MATARIC', 2014, p.21).

Além das definições de robótica presentes em Mataric'(2014), também adotamos em nossa pesquisa as concepções de robótica presentes em Barbosa (2016). Deste modo, consideramos os robôs como sistemas autônomos existentes no mundo físico, com capacidade de sentir o ambiente no qual está inserido e desempenhar ações em relação ao meio com o propósito de atingir objetivo(s).

Neste contexto, apresentamos como a robótica foi utilizada pelos estagiários de um Curso de Licenciatura em Matemática da Universidade Estadual de Goiás (UEG) durante as práticas de estágio-docência ocorridas em 2017. Ao longo de nossa experiência os estagiários

\footnotetext{
${ }^{3}$ Modelo da Representação: Noção muito instituída, muito pouco questionada e muito naturalizada no campo dos estudos da cognição: a ideia de que conhecer é representar um mundo preexistente. Segundo essa concepção tradicional da cognição, que é conhecida como modelo da representação, existe um sujeito do conhecimento, um objeto e uma capacidade de representar, de produzir uma espécie de cópia, equivalente a correspondente mental do mundo externo. É uma ideia que não tem nada de inquestionável, mas ela é muito enraizada em nós. É uma ideia cognitivista. A primeira coisa que é preciso ter clareza para entender a noção de políticas da cognição é que essa concepção representacional foi produzida historicamente. (Kastrup, 2012, p.53). A alternativa em relação ao modelo da representação é pensada a partir de algumas ideias de aprendizagem inventiva ligadas as políticas da cognição de Virgínia Kastrup, da teoria da autopoiese de Humberto Maturana e Franciso Varela, e também da filosofia da diferença de Gilles Deleuze.
}
(C) ETD- Educação Temática Digital
Campinas, SP
v.22
n.2
p. $406-420$
abr./jun. 2020 
construíram três robôs de forma coletiva em uma unidade do Sesi-Senai, também foram produzidas e discutidas algumas propostas educacionais de matemática nos encontros de estágio-docência na UEG, posteriormente as mesmas foram aplicadas pelos estagiários nas escolas-campo de estágio. Em relação às ações e práticas desenvolvidas durante nossa pesquisa, nos reportamos às concepções de Souza Junior (2000, p.290) quando afirma que "conhecimento é prática social e como tal deve ser compreendido".

Nossa pesquisa delineou-se segundo a perspectiva que denominamos como Educação Matemática Inventiva, que por sua vez, se embasa nas concepções de aprendizagem inventiva (KASTRUP, 2000-2015), na formação inventiva de professores (DIAS, 2008-2012) e na autopoieses ${ }^{4}$ (MATURANA E VARELA, 1995), onde buscamos direcionamento para o seguinte problema de pesquisa: Como a robótica foi utilizada pelos estagiários durante o desenvolvimento e a aplicação de suas propostas educacionais de matemática?

A temática da aprendizagem inventiva vem sendo discutida fortemente nos trabalhos desenvolvidos por Kastrup (2000-2015), que caracteriza a aprendizagem inventiva de forma diferente da aprendizagem por representação, já que esta última, se estabelece por meio do domínio de técnicas previsíveis e ações mecânicas com foco central na resolução de problemas.

Por outro lado, a aprendizagem inventiva não se limita a resolução de problemas, tendo como uma de suas características a invenção de problemas, que por sua vez, se manifestam nas experiências de problematização que ocorrem durante os processos de invenção de si e de mundo (KASTRUP, 2007).

As concepções de aprendizagem inventiva estão muito ligadas a autopoiese de Maturana e Varela (1995) que consideram os seres vivos como sistemas capazes de se autoproduzirem, constituindo-se concomitantemente como produtor e também como produto de si mesmo. A autoprodução dos seres vivos ocorre de forma autônoma e seus comportamentos são influenciados por suas experiências. A autoprodução de si é uma das características que diferem os seres vivos das máquinas, já que estas últimas não produzem a si mesmas.

A aprendizagem inventiva também é pensada como uma política cognitiva (KASTRUP, 2015), relacionada às experiências de problematização das quais emergem práticas e ações do conhecer. Isto posto, o sujeito ao inventar práticas e ações do conhecer vai também se autoproduzindo, inventando a si próprio, no seio destes processos, "a invenção de si é

\footnotetext{
${ }^{4}$ Autopoiese: Poiesis é um termo grego que significa produção. Autopoiese quer dizer autoprodução. A palavra surgiu pela primeira vez na literatura internacional em 1974, num artigo publicado por Varela, Maturana e Uribe, para definir os seres vivos como sistemas que produzem continuamente a si mesmos (Mariotti, S/D). Disponível em: http://www.dbm.ufpb.br/ marques/Artigos/Autopoiese.pdf). Acesso em: 07-02-2019.
} 
estimulada por um trato com a matéria que funciona como obstáculo na efetivação da obra" (KASTRUP, 2007, p.226).

Ao partirmos das considerações de Kastrup (2000-2012) consideramos a aprendizagem inventiva como o meio e o produto de ações e práticas do conhecer, que ao serem experimentadas, durante os processos de problematização, oportunizam aos sujeitos a invenção de si e de mundo. Também consideramos que "o conceito da aprendizagem inventiva é aquele que vai mais diretamente desembocar na ideia da formação inventiva" (KASTRUP, 2012, p.52).

Neste sentido, buscamos na aprendizagem inventiva uma alternativa ao modelo da representação durante o estágio-docência, uma vez que as práticas docentes ligadas a este modelo se manifestam apenas no nível da resolução de problemas, interpretação do mundo, reprodução de ações e práticas preexistentes segundo a representação de padrões préestabelecidos, desconsiderando uma das características mais singulares e evidentes dos seres humanos, que consiste no potencial de autoproduzir-se em meio as experiências e processos relacionados à invenção de a si e de mundo.

Problematizar o uso da robótica durante o estágio-docência em nossa pesquisa de doutorado em Educação, por meio das concepções relacionadas à autopoiese (MATURANA E VARELA, 1995) e formação inventiva de professores (DIAS, 2012) via aprendizagem inventiva (KASTRUP, 2000-2015), nos levou a apostar no que denominamos como Educação Matemática Inventiva.

Imersos neste contexto, apostamos na Educação Matemática Inventiva como o conjunto de ações e práticas do conhecer matemático aquecidas por um campo de problematizações, nas quais os sujeitos envolvidos vão coletivamente se autoproduzindo, durante a invenção de si e de mundo, o que denominamos como auto-formação-inventiva.

A Educação Matemática Inventiva não limita o uso dos conhecimentos matemáticos à resolução de problemas ou a representação do mundo, é antes de tudo o uso da matemática em prol da invenção de problemas e invenção de mundo. Neste contexto, para a Educação Matemática Inventiva o sujeito inventa a si mesmo ao utilizar os conhecimentos matemáticos em prol da invenção de problemas e/ou invenção de mundo. 


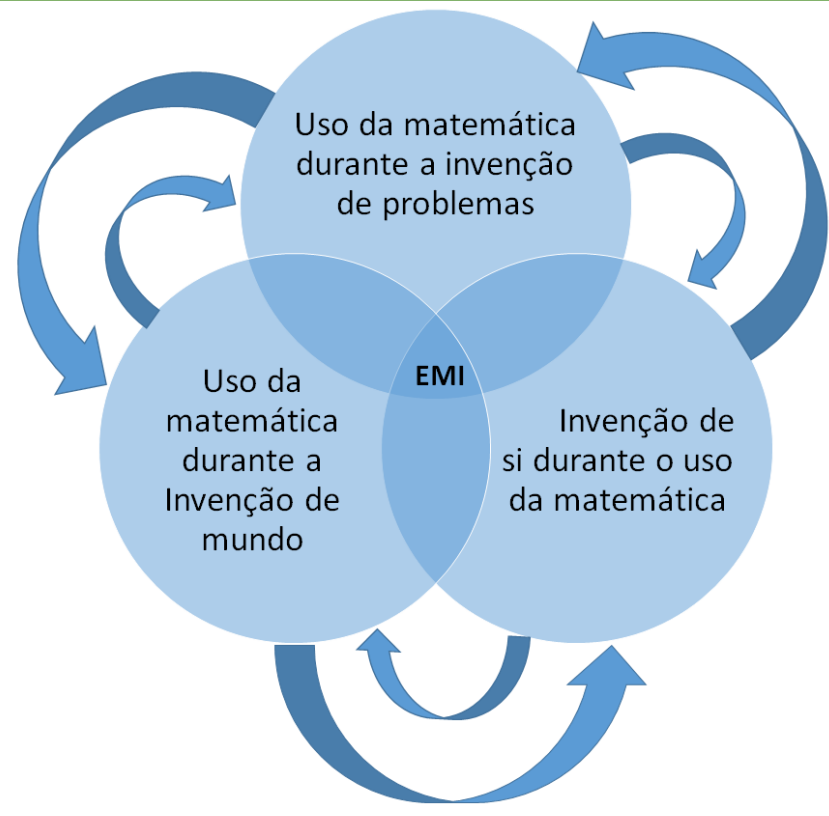

Figura1 - Educação Matemática Inventiva (EMI) Fonte: os autores

Apostamos na Educação Matemática Inventiva como uma via para a implementação e o desenvolvimento de ações e práticas de aprendizagem carregadas de originalidade, que emergem de situações ligadas à vida coletiva e às suas mais diversas formas de manifestação social, cultural e política, capazes de gerar a auto-formação-inventiva dos sujeitos envolvidos no campo da matemática, por meio das experiências de tateio com o meio/matéria, permeados por momentos de estranhamentos que desencadeiam a produção de deslocamentos em relação ao modelo da representação.

\section{PROCEDIMENTOS}

Os procedimentos que utilizamos em nossa pesquisa consistiram em cartografar, no sentido proposto por Passos, Kastrup \& Escóssia (2015), as produções dos estagiários durante o acompanhamento dos seguintes processos:

1. diagnóstico dos défices de aprendizagem dos alunos das escolas-campo de estágio por parte dos estagiários;

2. construção dos robôs em uma unidade do Sesi-Senai;

3. programação dos robôs em uma unidade do Sesi-Senai;

4. desenvolvimento coletivo das propostas educacionais com o uso da robótica na UEG;

5. participação de seminários relacionados ao desenvolvimento das propostas educacionais com o uso da robótica na UEG; 
6. reelaboração das propostas educacionais com o uso da robótica na UEG;

7. aplicação das propostas educacionais com o uso da robótica nas escolas-campo de estágio.

Os estagiários tiveram liberdade para produzirem, coletivamente, suas propostas educacionais de matemática com o uso dos robôs construídos e programados por eles com auxílio dos professores e alunos de uma unidade do Sesi-Senai. Os estagiários também tiveram liberdade para produzirem suas propostas educacionais a partir das necessidades de aprendizagem diagnosticadas por eles nas escolas-campo de estágio, e também para desenvolverem e aplicarem as mesmas durante as aulas de matemática nas escolas-campo de estágio.

Os estagiários construíram coletivamente três robôs com o propósito de explorarem os conteúdos de matemática a partir das dificuldades de aprendizagem apresentadas pelos alunos das escolas-campo de estágio. Assim, foram construídos o Robô Seguidor de Linha (Figura 2), o Robô Separador (Figura 3) e o Robô Empilhadeira (Figura 4).

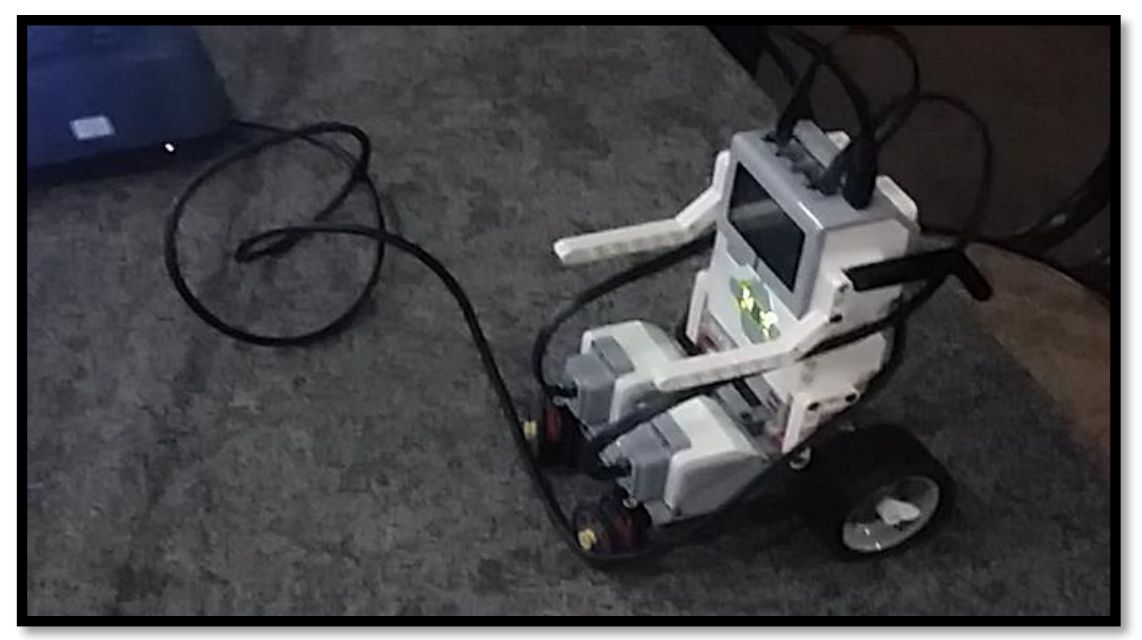

Figura 2 - Robô Seguidor de Linha Fonte: os autores

O Robô Seguidor de Linha foi construído e programado coletivamente por quatro estagiários, que denominados como A, B, C e D. De forma concomitante a construção e programação do Robô Separador ocorreu mediante ao trabalho colaborativo de três estagiários, que nomeamos como: E, F e G.

A seguir temos uma imagem do Robô Separador em movimento:

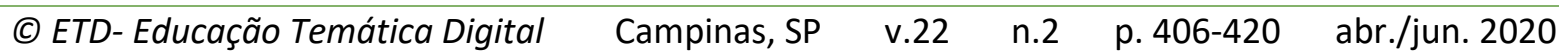




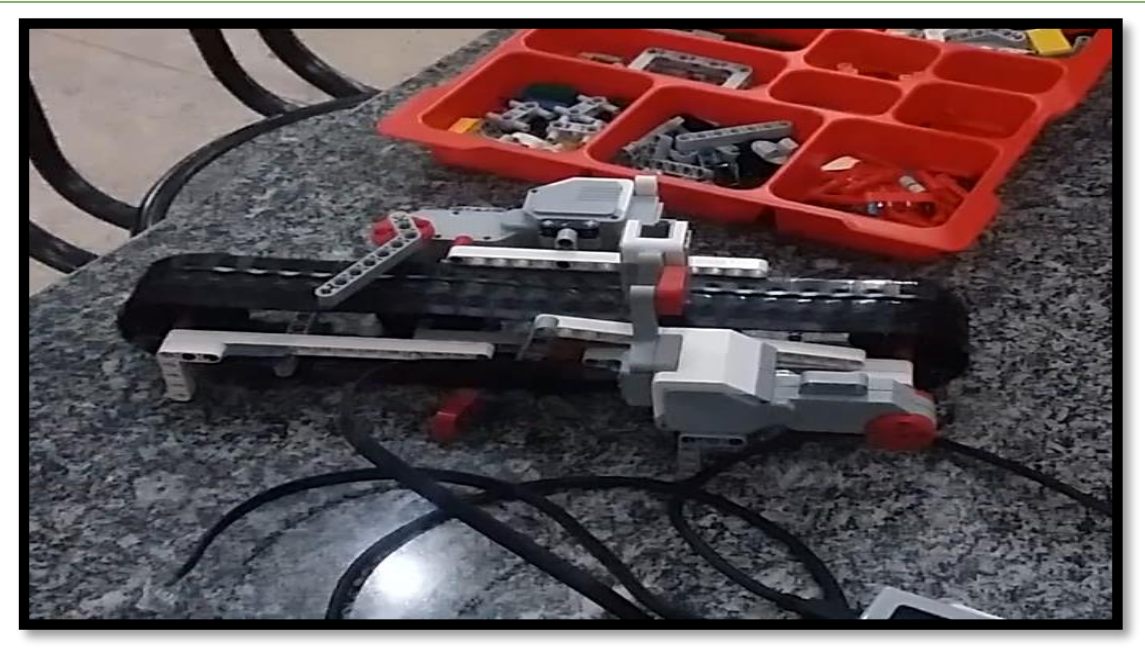

Figura 3 - Robô Separador Fonte: os autores

Em relação ao Robô Empilhadeira fruto do trabalho colaborativo dos estagiário que denominamos como $\mathrm{H}, \mathrm{I}, \mathrm{J}$ e $\mathrm{K}$, temos na figura a seguir o momento em que o mesmo foi colocado em movimento após ser construído e programado no espaço-tempo do estágiodocência:

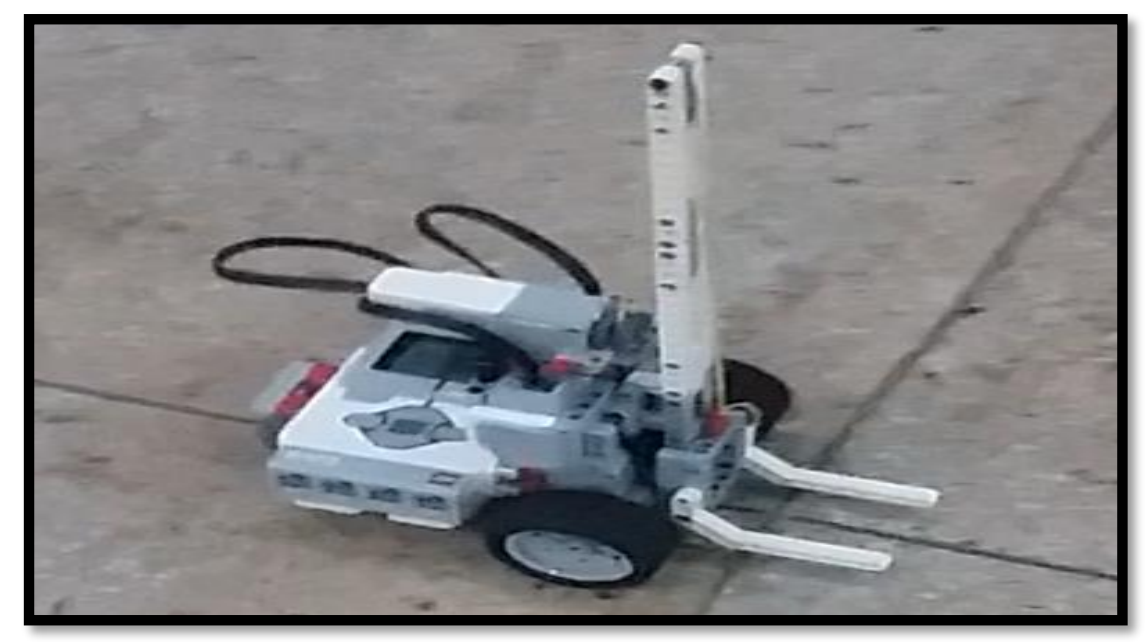

Figura 4- Robô Empilhadeira Fonte: os autores

Os três robôs foram construídos e programados coletivamente com peças do kit Lego EV3. As construções e programações ocorreram a partir de manuais, o que não consideramos como produções inventivas. No próximo item apresentamos como estes robôs foram utilizados pelos estagiários segundo a perspectiva da Educação Matemática Inventiva.
(c) ETD- Educação Temática Digital
Campinas, SP
v. 22
n.2
p. $406-420$
abr./jun. 2020 


\section{RESULTADOS}

Apresentamos a seguir os resultados obtidos em relação à utilização da robótica pelos estagiários durante o desenvolvimento e a aplicação de suas propostas educacionais de matemática. Primeiramente discorremos a respeito da forma como o Robô Seguidor de Linha foi utilizado, posteriormente passamos as experiências com o uso do Robô Empilhadeira e com o uso do Robô Separador.

A utilização do Robô Seguidor de Linha pelos estagiários A, B, C e D, ocorreram de formas distintas, uma vez que foram produzidas propostas educacionais de matemática para turmas diferentes do Ensino Médio a partir das necessidades específicas de aprendizagem dos alunos. Os estagiários A e B exploraram o Robô Seguidor de Linha com o objetivo de colocar em prática uma proposta educacional relacionada a um parque de diversões para cadeirantes, denominados por eles como Carpe Diem:

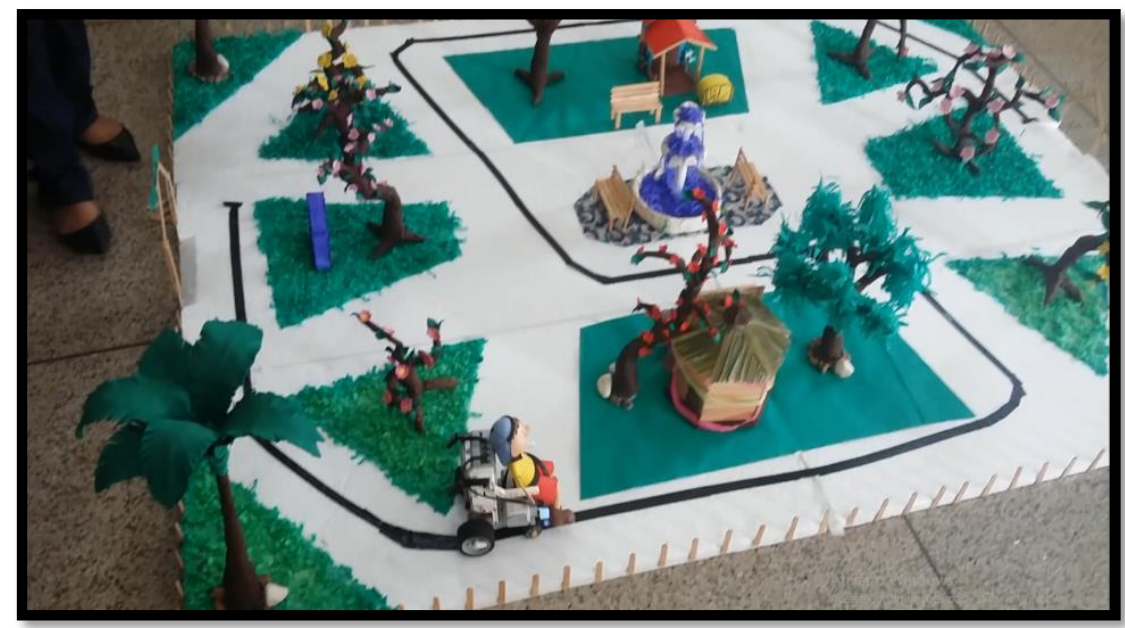

Figura 5 - Robô Seguidor de Linha no mundo inventivo Carpe Diem Fonte: os autores

Por meio da Figura 5 é possível observar que os estagiários A e B utilizaram a robótica como um dispositivo para inventar um mundo no qual o Robô Seguidor de Linha apresentouse como uma cadeira de rodas robótica, além disso utilizaram-se dos seus conhecimentos matemáticos para inventarem problemas de matemática, a partir das especificidades de cada turma de alunos.

Ao usar o Robô Seguidor de Linha para compor sua proposta educacional, o estagiário A, explorou o mundo inventivo (Figura 5) durante suas aulas de Matemática em uma turma do $3^{\circ}$ Ano do Ensino Médio de uma escola pública, que serviu como escola-campo de estágio. O estagiário A também inventou uma situação problema, na qual os alunos se viram como 
componentes de uma empresa responsável por transportar as dimensões relacionadas ao mundo inventivo para dimensões mais amplas, que pudessem ser utilizadas para construir um parque em tamanho real com o propósito de atender pessoas com deficiências físicas que utilizam cadeiras de rodas.

Os problemas inventados coletivamente durante os encontros de estágio propostos pelo estagiário $A$, aos alunos do $3^{\circ}$ Ano do Ensino Médio, por meio da situação inventiva envolvendo o uso do Robô Seguidor de Linha, tiveram como foco abordar os conteúdos de Equações de $1^{\circ} \mathrm{Grau}$, Equações de $2^{\circ}$ grau, Regra de Três, Área e Perímetro, entre outros.

O robô seguidor de linha usado para compor o mundo inventivo Carpe Diem, também foi utilizado pelo estagiário $B$, durante a aplicação de uma proposta educacional com problemas inventivos voltados a uma turma de $1^{\circ}$ Ano do Ensino Médio da mesma escolacampo de estágio, desta vez o estagiário B utilizou-se da robótica no mundo inventivo para explorar os conteúdos de Expressões Algébricas, Construções Geométricas no Plano Cartesiano, Funções do $1^{\circ} \mathrm{Grau}$, entre outros.

Os estagiários C e D utilizaram o Robô Seguidor de Linha para compor um mundo inventivo diferente do proposto pelos estagiários A e B já mencionados, o robô foi usado como um táxi que se deslocava de um ponto a outro de uma cidade inventiva, conforme podemos observar na Figura 6:

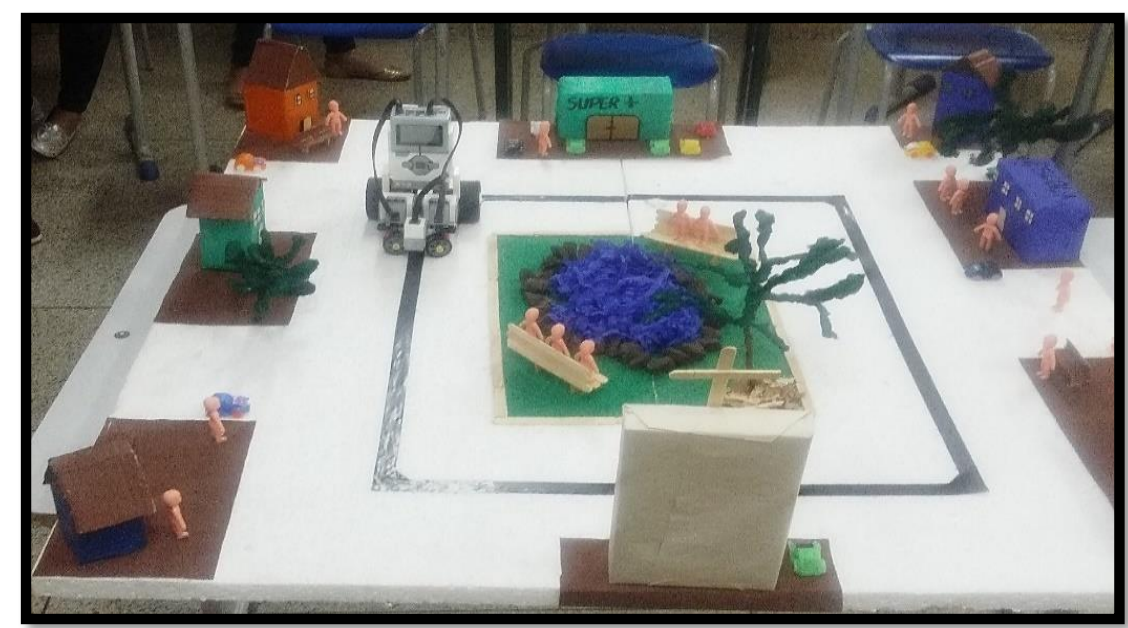

Figura 6 - Robô Seguidor de Linha usado como táxi em uma cidade inventiva Fonte: os autores

Os estagiários C e D aplicaram suas propostas educacionais de matemática com o uso do Robô Seguidor de Linha em duas turmas do $1^{\circ}$ Ano do Ensino Médio, a partir das necessidades específicas de aprendizagem destas turmas. Desta forma, foram criados alguns problemas inventivos relacionados à exploração do mundo inventivo no qual o Robô Seguidor de Linha foi usado como um táxi que se locomovia de um ponto a outro de uma maquete. 
Durante esta experiência foram trabalhados os conteúdos de: Coordenadas Cartesianas, Regra de Três e Funções do $1^{\circ} \mathrm{Grau}$.

Em nossa pesquisa os estagiários A, B, C e D utilizaram o Robô Seguidor de Linha para desenvolver ações e práticas de Educação Matemática Inventiva, concomitantemente, foram aos poucos inventando a si mesmos por meio de suas próprias experiências de problematização durante a invenção de mundo e invenção de problemas usados para compor suas propostas educacionais, a partir das especificidades de cada turma de alunos, o que gerou novos aprendizados aos estagiários. Nas palavras de Kastrup (2012, p.53) “O aprender começa como uma experiência de problematização, de invenção de problemas, ou de posição de problemas. E envolve também a invenção de mundo".

Em relação a utilização do Robô Empilhadeira pelos estagiários $\mathrm{H}, \mathrm{I}$, J e K durante as práticas relacionadas ao estágio-docência, apresentamos que o mesmo foi usado em uma escola-campo composta por alunos da Educação de Jovens e Adultos (EJA), no período noturno. Foi identificado a priori pelos estagiários $\mathrm{H}, \mathrm{I}, \mathrm{J}$ e $\mathrm{K}$ que alguns alunos exerciam profissões relacionadas ao uso de empilhadeiras. Partindo deste contexto e das especificidades de aprendizagem dos alunos, foram inventados alguns problemas de matemática relacionados ao uso do Robô Empilhadeira em um mundo inventivo, conforme figura a seguir:

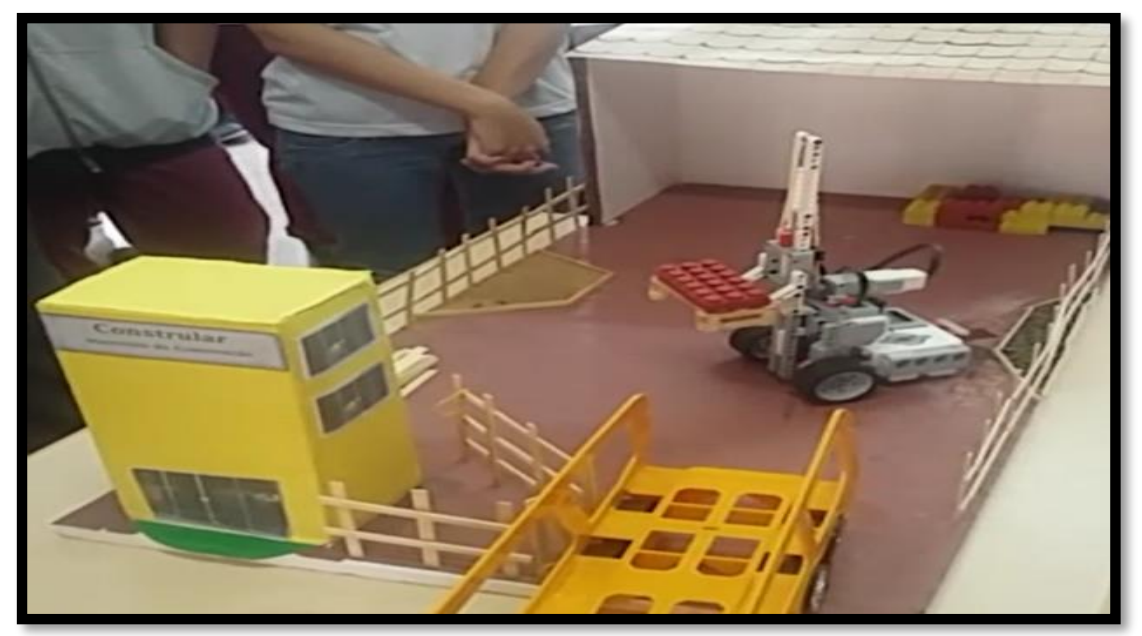

Figura 7- Robô Empilhadeira em atividade no mundo inventivo Fonte: os autores

Para desencadear a interação dos alunos da EJA com o mundo inventivo e também com o propósito de explorar alguns conteúdos que apresentavam dificuldades de aprendizagem, os estagiários $\mathrm{H}, \mathrm{I}, \mathrm{J}$ e $\mathrm{K}$ inventaram alguns problemas de matemática que foram explorados pelos alunos da EJA em sala de aula a partir do contato com o Robô Empilhadeira no mundo inventivo.

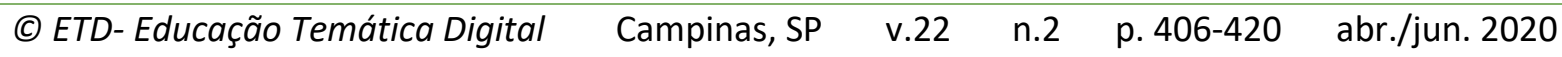


Os estagiários $\mathrm{H}, \mathrm{I}$, J e $\mathrm{K}$ ao usarem o Robô Empilhadeira desenvolveram ações e práticas carregadas de imprevisibilidade, relacionadas às especificidades de cada turma de alunos, este fato também ocorreu durante as outras experiências que acompanhamos em nossa pesquisa. Nesse sentido, consideramos a questão da imprevisibilidade como uma das características relacionadas às ações e práticas de Educação Matemática Inventiva, que por sua vez, não podem ser previstas a priori, mas podem ser acompanhadas e também examinadas a posteriori. A este respeito nos reportamos a Kastrup (2007, p. 217) quando afirma que:

A invenção de novas formas é sempre resultado da tensão entre as formas antigas e as afecções que ocorrem no plano molecular dos agenciamentos. É enquanto reverberam no plano das formas que as afecções ganham consistência e sentido, passando a configurar novas formas históricas, que não podem ser previstas a priori, mas devem ser examinadas caso a caso a, sempre a posteriori.

O desenvolvimento das ações e práticas de Educação Matemática Inventiva ocorridos durante a invenção das propostas educacionais de matemática com o uso da robótica, estiveram ligadas as situações específicas de aprendizagem dos alunos das escolas-campo de estágio. Este fato impossibilitou prever como as propostas educacionais de matemática seriam inventadas pelos estagiários com o uso da robótica, mas ao mesmo tempo, reforçou a necessidade de intensificarmos os encontros e os debates de ideias, com o propósito de tomarmos decisões colegiadas a respeito das ações e práticas de Educação Matemática Inventiva adotadas durante a pesquisa.

Em relação à utilização do Robô Separador, percebemos que dois estagiários (E e F) utilizaram-no para compor um mundo inventivo (Figura 8), relacionado a uma empresa, com o propósito de explorar conceitos relacionados ao conteúdo de Sequência Numérica em duas turmas do $2^{\circ}$ Ano do Ensino Médio de uma escola-campo de estágio.

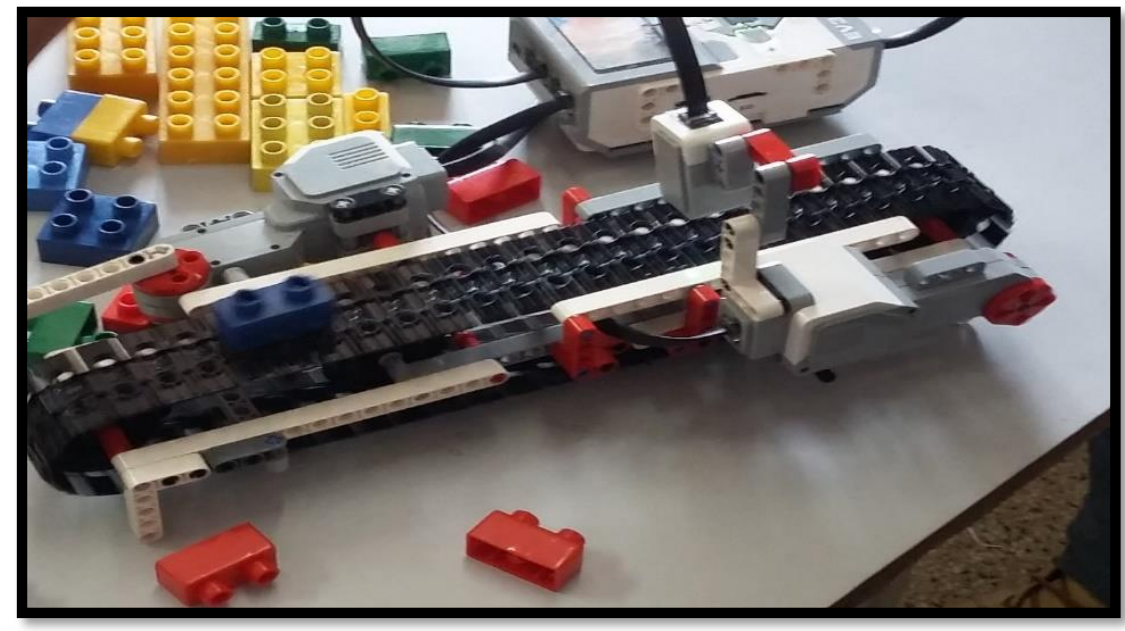

Figura 8- Robô Separador usado para compor uma empresa inventiva Fonte: os autores

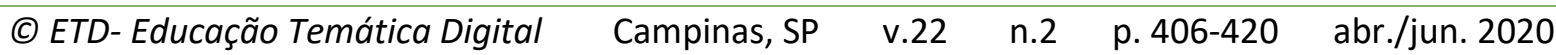


O estagiário $G$, também usou o Robô Separador em uma turma de $2^{\circ}$ Ano do Ensino Médio, com o propósito de explorar conceitos relacionados a Geometria Espacial durante uma situação inventiva relacionada ao trabalho em uma empresa, na qual era necessário utilizar o Robô Separador para avaliar peças defeituosas e separá-las de peças sem defeito.

Assim, como observamos nas experiência relacionadas ao uso do Robô Seguidor de Linha e do Robô Empilhadeira, os estagiários E, F e G, que utilizaram o Robô Separador durante a invenção de suas propostas educacionais, também não seguiram modelos prédefinidos, todos desenvolveram coletivamente ações e práticas diferentes a partir das especificidades das turmas de alunos das escolas-campo de estágio.

A partir do uso da robótica, os estagiários desenvolveram coletivamente ações e práticas de Educação Matemática Inventiva carregadas de diferença, em consonância com as concepções de formação inventiva de professores compartilhadas por Dias (2012, p.39) quando discorre que "para afirmar esta diferença é preciso forjar outra maneira de habitar o espaço-tempo da formação, que seja mais de fabricação e invenção de si e do mundo". Neste contexto, os estagiários forjaram maneiras diferentes de habitar o espaço-tempo do estágiodocência a partir da utilização da robótica como uma ferramenta para a produção de suas propostas educacionais de matemática.

O uso da robótica pelos estagiários ocorreu de maneira autônoma, o que consideramos na Educação Matemática Inventiva como uma das características mais evidentes da humanidade ao nos embasarmos nas concepções da autopoiese que:

\footnotetext{
enfatiza o fato de os seres vivos serem unidades autônomas. Usamos a palavra "autonomia" em seu sentido corrente - ou seja, um sistema é autônomo se puder especificar suas próprias leis, aquilo que é próprio dele. Não estamos sugerindo que os seres vivos são as únicas entidades autônomas: certamente não o são. Mas uma das características mais evidentes dos seres vivos é sua autonomia. Estamos propondo que o modo, o mecanismo que torna os seres vivos sistemas autônomos é a autopoiese, que os caracteriza enquanto tais. (Maturana e Varela, 1995, p.88).
}

Durante as experiências que acompanhamos, a robótica foi utilizada pelos estagiários de maneira inventiva, o que ocorreu durante a invenção de problemas e invenção de mundos. Neste processo os estagiários e as propostas educacionais de matemática produzidas com o uso da robótica não se apresentaram como polos prévios, mas como efeitos de ações e práticas do conhecer. Enquanto os estagiários utilizavam os robôs para inventar suas propostas educacionais, eles também inventavam a si mesmos ao experimentarem momentos de auto-formação-inventiva segundo a perspectiva que denominamos como Educação Matemática Inventiva. 


\section{CONSIDERAÇÕES FINAIS}

Com o propósito de compreendermos como a robótica foi utilizada pelos estagiários de um Curso de Licenciatura em Matemática durante o desenvolvimento e a aplicação de algumas propostas educacionais, constatamos durante nossa pesquisa que os estagiários utilizaram o Robô Seguidor de Linha, o Robô Empilhadeira e o Robô Separador de forma inventiva.

Durante as experiências, os estagiários tiraram proveito da robótica com o objetivo de produzirem propostas educacionais diferentes daquelas que estavam acostumados a presenciar em sala de aula. Nesse sentido, os estagiários não reproduziram modelos prontos, mas inventaram coletivamente suas próprias propostas educacionais de matemática a partir das necessidades específicas de aprendizagem dos alunos das escolas-campo de estágio.

Os estagiários ao se apropriarem da robótica não limitaram o uso da matemática a resolução de problemas, mas principalmente a problematização dos mundos inventivos por meio da invenção de problemas relacionados aos conteúdos do Ensino Médio. Ao utilizarem a matemática durante os processos de invenção de problemas e invenção de mundos, os estagiários foram aos poucos inventando a si mesmos durante o desenvolvimento de ações e práticas relacionadas ao uso da robótica.

Assim como os alunos, os estagiários também não sabiam de antemão os resultados dos problemas inventivos que foram aplicados nas escolas-campo de estágio, uma vez que era necessário os próprios alunos produzirem os dados iniciais a partir da exploração dos mundos inventivos com o uso da robótica. Este fato aproximou os alunos dos estagiários que se encontraram imersos dentro do mesmo campo de problematizações.

Ao utilizarem a robótica de maneira autônoma os estagiários experimentaram na prática processos de auto-formação-inventiva segundo a perspectiva que denominamos como Educação Matemática Inventiva. As experiências relacionadas ao uso da robótica no espaço-tempo do estágio-docência em matemática foram permeadas por problematizações e estranhamentos que levaram a produção de deslocamentos em relação ao modelo da representação. 


\section{REFERÊNCIAS}

BARBOSA, Fernando da Costa. Rede de aprendizagem em robótica: uma perspectiva educativa de trabalho com jovens. 2016. 366 f. Tese (Doutorado em Educação e Ciências Matemáticas) - Programa de Pós-Graduação em Educação, Universidade Federal de Uberlândia. 2016.

DIAS, Rosimeri de Oliveira. Formação inventiva de professores e políticas de cognição. In: Informática na Educação: teoria \& prática. Porto Alegre, v.12, n.2, jul./dez. 2009. ISSN digital 1982-1654 ISSN impresso 1516-084X. Disponível em: file:///D:/Users/User/Downloads/931341758-1-PB.pdf. Acesso em: 09-03-2018.

DIAS, Rosimeri de Oliveira. Formação inventiva de professores. Rio de Janeiro: Lamparina, 2012.

DIAS, Rosimeri de Oliveira. Deslocamentos na formação de professores: aprendizagem de adultos, experiência e políticas cognitivas. 2008. 224 f. Tese (Doutorado em Psicologia). Programa de Pós-Graduação em Psicologia, Universidade Federal do Rio de Janeiro, Rio de Janeiro, 2008.

KASTRUP, V. O devir-criança e a cognição contemporânea. Psicologia Reflexão e Crítica, Porto Alegre, v. 13, n. 3, 2000.

KASTRUP, V. A invenção de si e do mundo: uma introdução do tempo e do coletivo no estudo da cognição. Belo Horizonte: Autêntica, 2007.

KASTRUP, V. Aprendizagem da atenção na cognição inventiva. Psicologia \& Sociedade, Porto Alegre, v. 16. n. 3, set./dez. 2004.

KASTRUP, V. Políticas cognitivas na formação do professor e o problema do devir-mestre. Educação \& Sociedade, Campinas, v. 26, n. 93, set./dez. 2005.

KASTRUP, V. A invenção na ponta dos dedos: a reversão da atenção em pessoas com deficiência visual. Psicologia em Revista, Belo Horizonte v. 13 n. 1, jun. 2007.

KASTRUP, V. A aprendizagem inventiva. Entrevista por Juliano Reis Silveira. Edição Fábio Purper Machado. Disponível em: Acesso em: junho 2010. 17 KASTRUP, V; PASSOS, E. ESCÓCIA, L Pistas do método da cartografia: pesquisaintervenção e produção de subjetividade. Porto Alegre: Sulina, 2010. 207 p.

KASTRUP, V. Aprendizagem, arte e invenção, Psicologia em Estudo, Maringá, v. 6, n. 1, p. 1727, jan./jun. 2001.

KASTRUP, V. Conversando sobre políticas cognitivas e formação inventiva. In. DIAS, Rosimeri de Oliveira. Formação inventiva de professores. Rio de Janeiro: Lamparina, 2012.

KASTRUP, V; TEDESCO, S; PASSOS, E. Políticas da cognição. Porto Alegre: Sulina, 2015. 295 p.

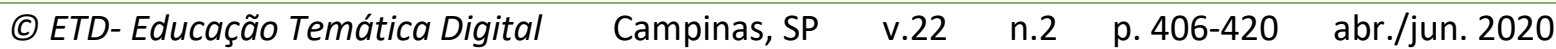


MATARIC', Maja J. Introdução à robótica / tradução Humberto Ferasoli Filho, José Reinaldo Silva, Silas Franco dos Reis Alves. São Paulo: Unesp/Blucher, 2014.

PASSO, E.; KASTRUP, V.; ESCÓSSIA, L. Pistas do método da cartografia: Pesquisa-intervenção e produção de subjetividade. Porto Alegre: Sulina, 2015. 207 p.

SOUZA JUNIOR. Arlindo José de. Trabalho Coletivo na Universidade: trajetória de um grupo no processo de ensinar e aprender Cálculo Diferencial e Integral. 2000. 323f. Tese (Doutorado em Matemática) - Faculdade de Matemática, - Universidade de Campinas, Campinas, 2000.

Revisão gramatical realizada por: Dayene Martins Morais Silva.

E-mail: professoradayene@hotmail.com 